\begin{abstract}
Resumo
Este texto tem por objetivo analisar a função do outro materno nos primórdios da vida psíquica do bebê, enfatizando a dimensão relacional e fundadora dessas trocas. Nessa perspectiva, pretendemos discutir a noção winnicottiana de preocupação materna primária para refletir sobre seu paradoxo: indiferenciação ou intersubjetividade? $A$ abordagem clássica e bastante conbecida de Winnicott é problematizada à luz de autores contemporâneos como Ogden e Roussillon, que propõem uma complexificação de seu pensamento, introduzindo na relação primária mãe-bebê a noção de intersubjetividade.

Descritores: preocupação materna primária; indiferenciação; intersubjetividade; psicanálise; relação mãe-bebê.
\end{abstract}

\section{PRIMEIROS TEMPOS DA MATERNIDADE: INDIFERENCIAÇÃO OU INTERSUBJETIVIDADE NA RELAÇÃO PRIMITIVA COM O BEBÊ?}

\author{
Natália De Toni Guimarães dos Santos \\ Silvia Abu-Jamra Zornis
}

DOI: http://dx.doi.ors/10.11606/issn.1981-1624.v19i1p78-90

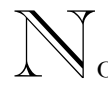
nismo e pela multiplicidade de destinos femininos possíveis, novos desafios são lançados à maternidade. A mulher atual vem sendo convocada a manter-se como protagonista nos cuidados infantis ainda que detectemos uma tendência de, aos poucos, os homens irem se aproximando dessa tarefa -, mas sofre também diversas pressões sociais para trabalhar, estar bonita, feliz, realizada etc. (Badinter, 2011). Nesse sentido, diante de um cenário social em que a mulher é exigida em suas múltiplas facetas, faz-nos questão pensar como a exigência inerente à função materna, que implica em grande devoção e dedicação ao bebê que, no início, é extremamente dependente dos cuidados maternos, é vivenciada pelas mulheres de hoje. Será que.

Doutoranda em Psicologia Clínica na Pontifícia Universidade Católica do Rio de Janeiro (PUC-RJ), Rio de Janeiro, RJ, Brasil.

- Docente da Pontifícia Universidade Católica do Rio de Janeiro (PUC-RJ), Rio de Janeiro, RJ, Brasil. 
na atualidade, sendo a mulher autora de múltiplos investimentos no mundo, ainda podemos falar de uma experiência feminina de indiferenciação em relação ao bebê?

A dependência objetiva da criança ao nascer foi constatada ainda nos primórdios do pensamento freudiano, quando, no "Projeto para uma psicologia científica", ao falar da primeira experiência de satisfação, Freud (1895/1977a) aponta que a prematuração biológica do bebê tem como contrapartida fundamental a dependência ao outro, àquele que irá realizar para o infante a ação específica capaz de saciar suas necessidades orgânicas. Sem a ajuda desse outro experiente, o bebê sucumbiria, incapaz de alcançar a satisfação de suas necessidades com seus próprios recursos. Nesse movimento, o outro, além de garantir a sobrevivência ao nível biológico, possibilita o processo de constituição subjetiva do bebê ao propiciar que este último vivencie, nesse encontro, uma experiência erógena, despertando sua sexualidade e a construção do seu aparelho psíquico.

Freud (1905/1977b), no entanto, enveredando pelos caminhos da instauração do desejo sexual por apoio na autoconservação, traz à cena dos primórdios da vida psíquica o conceito de autoerotismo, que postula a atuação anárquica das pulsões parciais cuja satisfação sexual pela via do prazer de órgão prescinde do objeto. Dessa maneira, ainda que a relação com o objeto esteja colocada na base do processo que origina o autoerotismo como condição de possibilidade para seu estopim, o pai da psicanálise salienta os processos intrapsíquicos e de natureza sexual na constituição do sujeito, dando pouca ênfase à função do objeto nesse processo. Em nossa visão, a qualidade do encontro com o objeto, ou melhor, com a mãe ou quem exerce essa função, e o prazer especificamente oriundo desse encontro, não se reduz à descarga da autoconsevação e ao prazer sexual (Roussillon, 2008), mas refere-se ao desenvolvimento do que Winnicott denominou "self inicial do bebê".

A dependência de que se trata no campo do desenvolvimento do self não é a dependência mobilizada pelo desejo sexual, mas a dependência do vínculo primário com a mãe que possibilita os processos de integração, já que no início o bebê vive um estado de não integração. Nesse estágio inicial do desenvolvimento emocional primitivo, denominado "dependência absoluta", nenhum objeto externo ao self é reconhecido, pois ainda não há self, ele é apenas potencial. Antes dos seis meses, aproximadamente, os bebês estão num estado de indiferenciação em relação ao ambiente, de modo 
que a separação da mãe não os afeta da mesma maneira que o faria depois de seis meses (Winnicott, 1959/1988, citado por Valler, 1990).

"Um bebê é algo que não existe (separado dos cuidados maternos)" (Winnicott, 1960a, p. 39, citado por Ogden, 1996). Essa máxima winnicottiana ressalta que não se pode pensar em um bebê sem considerar a relação primária que se estabelece entre este e seu cuidador, essa prótese fundamental, que precisa acompanhar, sustentar e conter o pequeno corpo composto de partes não integradas e sem limites dentro/fora, eu/outro estabelecidos. Há, portanto, uma não integração primária, mas ser conhecido e reconhecido pelo outro confere à criança pequena um sentimento de integração, na medida em que o cuidador, de certa maneira, junta seus pedaços por meio da técnica do cuidado infantil: o bebê é manipulado, banhado, embalado e nomeado, e também vive experiências pulsionais que tendem a tornar a personalidade una a partir do interior.

Segundo Winnicott (1983), o desenvolvimento emocional primitivo considera a hereditariedade, que consiste no potencial inato de desenvolvimento e maturação do bebê; e o ambiente, que apoia, falha ou traumatiza. Entre a hereditariedade e o ambiente está o bebê que, conforme citado, não existe sozinho, mas apenas enquanto ser dependente dos cuidados de outro ser humano, vivendo e acumulando experiências com base nessa relação.
Nesse sentido, o tema da relação primitiva mãe-bebê é de máxima importância, e só gradualmente cede o primeiro lugar para o tema do bebê como ser independente. Mas e a mãe? A discussão sobre o estatuto dessa relação primária, no que tange a experiência subjetiva da mãe, merece um olhar atento e cuidadoso.

Assim, a proposta deste artigo é refletir sobre a posição subjetiva da mãe nos primórdios da vida da criança, com base no conceito winnicottiano de "preocupação materna primária”. Parte-se da abordagem clássica e bastante conhecida de Winnicott a esse respeito para então problematizá-la à luz de autores contemporâneos como Ogden e Roussillon que, sem dúvida, concordam com Winnicott, mas propõem uma complexificação de seu pensamento, introduzindo nesse campo da relação primária mãe-bebê uma noção de intersubjetividade. Embora esse termo esteja muito em voga atualmente, utilizado de maneiras muito diversas e, às vezes, pouco precisas e fundamentadas, o que queremos apresentar é o que podemos chamar de "rudimentos da intersubjetividade", entendida como um campo entre sujeitos. $\mathrm{O}$ que interessa evidenciar é exatamente o "entre", deixando em suspenso "sujeitos". A aposta deste artigo, então, é que, mesmo no estado de preocupação materna primária, vigora para a mãe, ao lado de momentos de certa indiferenciação, também uma experiência intersubjetiva, onde há 
dois. O bebê, nesse sentido, é entendido como um parceiro ativo da relação, interagindo, afetando e sendo afetado. Nessa perspectiva, não cabe pensar uma alienação ao Outro, já que a mãe se coloca numa posição de continuidade intersubjetiva, igualando-se ao bebê como parceira na relação, embora, evidente, carregue as peculiaridades de uma subjetividade adulta.

O ambiente, nesse sentido, não faz a criança, mas possibilita ou não que ela concretize seu potencial. Assim, para que o potencial inato se desenvolva física e emocionalmente, é preciso um ambiente de facilitação que se adapte às necessidades cambiantes do bebê. Esse ambiente é, inicialmente, a mãe em estado de preocupação materna primária (Winnicott, 1956/1978a) que, graças a sua devoção, proporciona ao bebê a experiência de onipotência, fazendo-o progredir no processo de integração.

Já ao final da gravidez e nos primeiros tempos após o nascimento, a mãe está preocupada com (ou devotada a) o cuidado de seu bebê, que de início parece ser parte dela mesma. Está muito identificada com o filho e sabe o que ele está sentindo com base em suas próprias experiências como bebê, estando também ela própria, a mãe, em um estado dependente e vulnerável. Para entrar nesse estado organizado que, se não fosse na gravidez, seria uma doença, e, portanto, para sair dele quando o bebê a libera, seria necessário que a mulher fosse saudável. Algumas mulheres não conseguem atingir esse estado de adaptação delicada e sensível às necessidades iniciais do bebê, ou então a atingem com um filho e não com outro. Elas não são capazes de se preocupar com seus bebês a ponto de excluir outros interesses de maneira normal e temporária. Outra pessoa, no entanto, que também possa ser capaz de ficar doente no sentido de apresentar uma "preocupação materna primária" pode ser capaz de se adaptar suficientemente bem, por ter alguma capacidade de se identificar com o bebê (Winnicott, 1956/1978a).

Se a mãe se adapta às necessidades do bebê, a provisão é feita naturalmente sem que a criança tenha delas qualquer consciência. Se a mãe, por meio de sua capacidade de identificação, puder proteger o bebê de invasões ambientais, ele poderá, a seu tempo, por meio de um gesto espontâneo proveniente do self verdadeiro em potencial, vir a descobrir o ambiente que o cerca. Para isso, é fundamental a experiência de ilusão nos primeiros tempos da vida: a adaptação materna capacita a mãe a colocar seu seio de encontro à projeção (alucinação) que o bebê está pronto a fazer do seio bom. Se essa 
experiência for vivida com sucesso, o bebê terá condições também de aceitar momentos de desilusão gradual, tal como o desmame. É preciso que mãe e criança vivam uma experiência juntos, que ela possa prover o seio ao bebê no momento mesmo em que ele o deseja. Desse modo, o bebê começa a construir uma capacidade de evocar o que está realmente disponível.

Para que esta ilusão se produza na mente do bebê, é necessário que um ser humano se dê ao trabalho de trazer o tempo todo o mundo até o bebê de forma compreensiva e de maneira limitada, adequada às necessidades do bebê. Por essa razão, um bebê não pode existir sozinho, psicológica ou fisicamente, necessitando realmente de uma pessoa que cuide dele no início. (Winnicott, $1945 / 1978$ b, p. 281)

A mãe que desenvolve o estado de preocupação materna primária, essa provisão ambiental suficientemente boa, fornece um setting no qual a constituição do bebê pode se realizar. Suas tendências de desenvolvimento começam a se revelar, e o bebê pode experimentar um movimento espontâneo e dominar as sensações apropriadas a essa fase inicial da vida, organizando o "sentimento" existência, antes mesmo do estabelecimento de padrões pulsionais (Winnicott, 1956/1978a). Quando a mãe fornece uma adaptação suficientemente boa, a própria linha de vida do bebê é pouco perturbada pela necessidade de ter que reagir à invasão ambiental, o desenvolvimento do ego não sofre perturbações excessivas, e a criança tem o sentimento de continuidade do ser, adquirindo uma sensação de segurança e de ser amado. Por outro lado, fracassos maternos produzem fases de reação à invasão que interrompem o "continuar a ser" do bebê, representando uma ameaça de aniquilação do self-e não uma frustração (sexual).

Ao fornecer uma sustentação adequada - bolding -, a mãe, identificada com o bebê, possibilita que fragmentos da atividade motora e sensorial comecem a se congregar (Winnicott, 1945/1978b). Aos poucos, junto aos rudimentos de uma elaboração imaginária sobre o funcionamento do próprio corpo, possibilita momentos de integração, de continuidade do ser. Para Ogden (2010), o "continuar a ser" winnicottiano traduz a qualidade mais precoce de vivacidade. Essa expressão totalmente verbal transmite o sentimento do movimento da experiência de estar vivo numa época em o bebê ainda não se tornou sujeito. Trata-se de uma experiência no tempo, uma continuidade temporal somente possível na medida em que a mãe suficientemente boa, por meio de sua função de sustentação do ser

82 Estilos clin., São Paulo, v. 19, n. 1, jan./abr. 2014, 78-90. 
do bebê no tempo, absorve o impacto do aspecto não-eu o tempo, que seria sentido como uma invasão pelo bebê, que rasgaria o tecido fino de sua continuidade de ser.

Assim, "uma das principais funções do holding físico e psicológico inicial da mãe inclui o isolamento do bebê em seu estado de continuar a ser da alteridade implacável, inalterável do tempo" (Ogden, 2010, p. 122). Num estágio em que a consciência do não-eu é insuportável e perturbadora de sua continuidade de ser, o tempo, em todas as suas formas, é uma invenção humana que nada se relaciona com a experiência do bebê. Nesse momento a função materna se apresenta enquanto participação da mãe na sensação do tempo do bebê, transformando para ele o impacto da alteridade do tempo e criando a ilusão de um mundo no qual o tempo é medido quase totalmente nos termos dos ritmos físicos e psicológicos do bebê. Dessa maneira, a sustentação suficientemente boa do sentimento de continuidade do ser do bebê somente será possível, no princípio, se a mãe se encontrar nesse estado de preocupação materna primária.

Em seu holding mais precoce do bebê, a mãe, com um alto custo emocional para si mesma, absorve o impacto do tempo (por exemplo, privando-se do sono de que necessita, do tempo de que necessita para renovação emocional oriunda de estar com outrem que não o bebê, e do tempo de que necessita para fazer alguma coisa sozinha que não envolva o bebê). (Ogden, 2010, pp. 122-123)

Como se pode imaginar, essa não é uma tarefa fácil, pois representa uma anulação de si própria no esforço inconsciente de não atrapalhar o bebê. A constituição subjetiva se realiza, desse modo, no silêncio da dimensão subjetiva da mãe, na qualidade de uma presença materna discreta e silenciosa, fundamental para que o potencial inato da criança possa se desdobrar em seu gesto espontâneo. Essa anulação de si, na mãe, é correlata dos momentos mais precoces da vida do bebê, em que este se encontra bastante vulnerável às invasões do ambiente e às vivências de aniquilação do self.

Nessa condição especial de sensibilidade aumentada, que possibilita sentir-se no lugar do bebê, a mãe se retrai, vive algo como uma dissociação ou uma fuga, ou mesmo uma perturbação a um nível mais profundo, tal como um episódio esquizoide, no qual algum aspecto da personalidade assume temporariamente o controle. Nas palavras de Ogden (2010):

Como é verdade em relação ao estado do bebê de continuar a ser, a preocupação materna primária é um estado sem sujeito. Isso deve ser assim porque a presença sentida da máe-como-sujeito rasgaria o delicado tecido do continuar a ser do bebê. Na preocupação materna primária não existe algo como uma mãe. 'A mãe sente a si mesma no lugar do bebê' (Winnicott, 1956 apud Ogden, 2010) e, assim, remove-se não apenas da experiência que o bebê tem dela, mas também, em grande medida, da 
experiência que ela tem de si própria.

(Ogden, p. 122, itálico nosso)

Esse movimento materno de descentramento de si mesma em prol de uma identificação fina com o bebê, a ponto de a mãe estar num "estado sem sujeito" faz pensar que tem-se nesse momento inicial do relacionamento mãe-bebê vivências de indiferenciação entre ambos. Para a mãe, o bebê e ela mesma são experimentados como a mesma coisa. Embora seja conhecido que diferentemente do bebê em estado de não integração e indiferenciação em relação ao ambiente, a mãe, adulta, já atingiu um grau de maturação e de integração do self que a constitui enquanto um sujeito singular, a mãe em estado de preocupação materna primária se encontra regredida a esse estágio primitivo da vida psíquica no qual se encontra o bebê, experimentando ela mesma vivências de não integração e de indiferenciação em relação a seu bebê.

Assim, em outro artigo, em que apresenta sua concepção a respeito do sujeito winnicottiano, Ogden (1996) afirma que ao se colocar no lugar do bebê para responder às suas necessidades, a mãe corre o risco de perder uma sensação de ancoragem em si mesma como indivíduo separado. Nesse sentido, para o autor, a preocupação materna primaria implicaria uma dialética de estar-em-um estar separado, uma interdependência entre subjetividade e intersubjetividade, salientando um ponto de vista que,

84 Estilos clin., São Paulo, v. 19, n. 1, jan./abr. 2014, 78-90. 
com base em Winnicott, vai mais além deste, já que apresenta as diferentes nuances do materno na relação primitiva com o bebê. Se, por um lado, a subjetividade materna cede lugar à do bebê, permitindo à mãe vivenciar as necessidades do bebê como próprias, ao mesmo tempo, é preciso que a mãe possa manter um senso suficiente de sua própria subjetividade distinta para servir de intérprete da experiência do bebê, fazendo sua alteridade ser sentida, mas não considerada. "A intersubjetividade que subjaz à preocupação materna primária implica uma forma precoce da dialética da unicidade (oneness) e dualidade (twoness): a mãe é uma presença invisível (invisível mas sentida)." (Ogden, 1996, p. 46).

O sujeito, nessa perspectiva, nasce com base nas tensões dialéticas de unidade e separação, internalidade e externalidade, ou seja, no espaço entre mãe e bebê, o que marca a interdependência entre os campos da subjetividade e da intersubjetividade. O estado de "continuidade do ser" na criança, ou "eu-dade", então, surgiria da experiência da simultaneidade paradoxal de estar-em-um e estar separado, na medida em que, por meio dessa relação com a "mãe devotada comum" (Winnicott, 1967/1975), o estado psicológico da mãe se nivela ao do bebê na constituição da unidade dual mãe-bebê. Assim, a unicidade é o contexto necessário para a dualidade, e a dualidade salvaguarda a experiência da unicidade - ao propiciar uma negação essencial disso.
Essa leitura de Ogden parece uma complexificação do pensamento winnicottiano, que enfatiza o aspecto de indiferenciação entre mãe-bebê, vivida tanto do lado do bebê como do lado da mãe, apesar das enormes diferenças psicológicas entre a identificação da mãe com o bebê, e a dependência do bebê com relação à mãe - que não envolve identificação, um estado de coisas complexo, inaplicável aos estádios iniciais da infância (Winnicott, 1956/1978a). Apesar de rudimentar e, portanto, de não estar referida a uma relação propriamente entre sujeitos, Ogden vê nesse estado de preocupação materna primária a constituição de um campo de intersubjetividade entre mãe e bebê, ressaltando que a mãe deve, sim, ser uma presença invisível, porém sentida, capacitada a "devolver" para o bebê seus estados sensoriais e afetivos.

$\mathrm{Na}$ abordagem winnicottiana da relação primitiva entre mãe e bebê, sua teorização a respeito do papel de espelho da mãe (Winnicott, 1967/1975) apresenta com mais clareza a ideia de uma relação intersubjetiva entre os dois parceiros. Nesse trabalho, Winnicott afirma que "no desenvolvimento emocional individual, o precursor do espelho é o rosto da mãe" (Winnicott, $1967 / 1975$, p. 153 , itálicos do autor). Ao começar a perceber o mundo a sua volta, o bebê olha para o rosto da mãe $\mathrm{e}$, ao fazer isso, normalmente, ele vê a si mesmo. "Em outros termos, a mãe está olhando para o bebê e aquilo com o que ela se parece se acha relacionado com 
o que ela vê ali." (Winnicott, 1967/1975, p. 154, itálicos do autor). "É o derivado complexo do rosto que reflete o que há para ser visto." (Winnicott, 1967/1975, p. 161).

Nem sempre é o bebê que seu rosto reflete, mas seu próprio humor ou a rigidez de suas defesas. "Muitos bebês têm a experiência de não receber de volta o que estão dando. Eles olham e não veem a si mesmos." (Winnicott, 1967/1975, p. 154). A mãe que fracassa ao refletir o bebê não lhe devolve seu próprio mundo interno, mas o invade com sua reação, com seu próprio gesto enquanto sujeito em sua alteridade radical, numa posição de exterioridade que não permite a captação e devolução para o bebê de seus estados físicos e psicológicos. "Se, por outro lado, o rosto da mãe não reage, então o espelho constitui algo a ser olhado, não a ser examinado." (Winnicott, 1967/1975, p. 155). Olhar e ver-se nos olhos do outro é fundamental para o sentimento de existência.

Observa-se, assim, que tanto no estado de preocupação materna primária quanto no papel especular da mãe, a mãe desaparece como objeto separado e simplesmente serve de extensão narcísica para o bebê. No entanto, no papel especular da mãe, o espelhamento não é uma relação de identidade: o que a mãe parece para o bebê "está relacionado com" - não é o mesmo que ela vê no bebê. Trata-se de uma "relação de relativa semelhança e, portanto, de relativa diferença" (Ogden, 1996, p. 48). O bebê vê a si mesmo como objeto, como outro, por meio da mãe, na medida em que a mãe-espelho possibilita a vivência da diferença entre eu e mim: self-como-sujeito e self-como-objeto. As observações que o bebê faz de si mesmo no reflexo dele na mãe produz os rudimentos da experiência de autoconsciência, autorreflexão, ou seja, a percepção de uma "mim-dade" observável (Ogden, 1996, p. 48). Nessa perspectiva, o sujeito surge sempre no contexto da intersubjetividade, refletido no rosto da mãe e, portanto, descentrado de si mesmo, já que nesse movimento o sujeito autorreflexivo é simultaneamente constituído e descentrado de si mesmo.

Essa ideia de uma relativa semelhança e, então, simultaneamente, de uma relativa diferença na resposta materna em relação ao sujeito, remete à abordagem de Roussillon (2008) da dependência primitiva do bebê com base no conceito de homossexualidade primária em duplo. Esse conceito "significa que as primeiras

86 Estilos clin., São Paulo, v. 19, n. 1, jan./abr. 2014, 78-90. 
formas de organização do vínculo primitivo, que a 'base', portanto, da experiência de satisfação primitiva, supõe a construção e o encontro de um objeto 'duplo' de si” (Roussillon, 2008, p. 7). O autor se propõe, assim, a articular a dimensão freudiana da pulsão e a metapsicologia winnicottiana, pensando a função do objeto na introdução do pulsional no sujeito. Para isso, aponta que a experiência de satisfação descrita por Freud não pode se limitar ao prazer oriundo da satisfação orgânica e da satisfação sexual, como afirmado anteriormente.

A particularidade fundamental da experiência de satisfação é o que ocorre no seio da "coreografia" do encontro quando o objeto aceita desempenhar a função de espelho primário, que Winnicott foi o primeiro a reconhecer. Essa refletividade no seio da relação primitiva aponta para a existência de um prazer específico do encontro e para uma necessidade de "compartilhamento de prazer". Essa recíproca do prazer - que não significa simetria, já que os meios engajados por um e pelo outro não são similares - é condição sine qua non para que o afeto de prazer se constitua, ou seja, para que seja experimentado como tal e construa representantes psíquicos. A base dessa relação em que o outro é percebido em seu movimento de espelhamento do sujeito, funcionando como um duplo, pode ser chamada de "homossexualidade primária" porque o prazer é sentido no ballet desse encontro onde há uma relação de semelhança, mas não há confusão entre o sujeito e o duplo. Roussillon (2008) explica:

Um duplo é um outro, é um outro sujeito. Se o duplo não é um outro, não pode ser um duplo. A referência ao duplo exclui a confusão psíquica, não se trata aqui de uma forma de indiferenciação nem de uma forma de "fusão". Mas o duplo é um semelhante, ele se torna, é tornado, semelhante no encontro e nas condiçóes desse encontro. A hipótese de uma relação primitiva homossexual em duplo supóe que o outro primordial seja encontrado no início como semelhante, no que ele é semelhante, mas também no que ele "se propóe" a ser semelhante, no que ele "se faz" semelhante ao sujeito, no que ele aceita se tornar semelhante, que ele aceita "refletir" e "partilhar" os mesmos estados de ser, os mesmos estados de espírito. (Roussillon, p. 114, tradução nossa)

O duplo é, portanto, um espelho "aproximado" e não exato, mas "é, sobretudo, um espelho se ajustando, um espelho que se define pelo próprio processo de ajustamento." (Roussillon, 2008, p. 114, tradução e itálico nosso). Aos gestos, às mímicas e às postue ras de um correspondem os gestos, as mímicas e as posturas do outro, comunicando-se e transmitindo-se um cortejo de sensações, assim compartilhadas e reguladas. Essas trocas dentro/fora e entre dois "sujeitos" são mediatizadas pelo corpo de um e do outro, pela maneira singular como um e outro habitam seus corpos e como o engajam libidinalmente em sua relação desde a origem. $O$ ballet 
desse encontro mãe-bebê se constitui, então, justamente na tendência relacional que se traduz num movimento de busca da sintonia fina entre os dois parceiros de modo que cada um, o bebê particularmente, possa antecipar os movimentos ou variações do outro.

“É o ritmo, primeiro nível de organização de uma forma de temporalidade, que torna possível certa 'previsibilidade' da mãe e de seus movimentos." (Roussillon, 2008, p. 119, tradução nossa). Assim, o bebê, em sua imaturidade, só pode antecipar os processos manifestados por sua mãe em certa medida, mas pode-se dar crédito ao aparelho psíquico da mãe, que atingiu uma complexidade adulta, de poder cumprir essa tarefa sem demasiadas dificuldades, desde que ela esteja em contato com seus movimentos profundos e espontâneos (Roussillon, 2008). Dessa maneira, para estar na condição de duplo do bebê, enquanto semelhante, mas também diferente, resguardando seu lugar de alteridade, a mãe precisa estar em contato com ela mesma, com sua própria subjetividade, na qual encontrará os recursos necessários para estabelecer sua função de espelho em relação ao bebê e propiciar o compartilhamento sensorial com o bebê que, aos poucos, vai se complexificando e possibilitando os processos de simbolização primária na criança. Para tanto, a mãe também precisa experimentar nela mesma, em contato consigo mesma, o prazer do compartilhamento da sensação e do afeto no encontro com seu bebê. 
Nesse sentido, se o duplo deve ser suficientemente "mesmo" para ser um duplo do sujeito, mas também suficientemente "outro" para não ser o próprio sujeito, não podemos mais manter a ideia de uma indiferenciação primitiva, na qual o bebê não perceberia a exterioridade do objeto - pesquisas recentes, segundo Roussillon (2008), mostram que o bebê "percebe", desde o início, uma forma de "mãe" e que tem uma "preconcepção" inata de alguém diferenciado dele, de "outro" com quem a questão da construção de um vínculo de apego, de um encontro, coloca-se. De maneira análoga, também não é possível conceber stricto sensu que a mãe se encontraria num estado fusional em relação a seu bebê, já que nesse encontro sua subjetividade não está anulada, mas apenas silenciada, e que esta é imprescindível para que a mãe alcance o estatuto de duplo do bebê.

Verifica-se, com base nesse pensamento dialético e complexo que evoca a ideia de uma relativa semelhança e, portanto, de uma relativa diferença, que a função materna nos primórdios da vida psíquica da criança se desenvolve na oscilação e na articulação entre dimensões de indiferenciação e de intersubjetividade primárias. A intersubjetividade de que se trata nesse momento precoce é, obviamente, "uma forma particular de intersubjetividade na qual o ser da mãe é vivido simultaneamente como uma extensão do bebê e como outro com respeito a ele." (Ogden, 1996, p. 51). Essa perspectiva de Roussillon da homossexualidade primária em duplo mostra, assim, o valor de se pensar num campo de intersubjetividade - ainda que primária, incipiente e calcada na noção de duplo - entre mãe e bebê. Talvez possa-se afirmar que este seria o rudimento da intersubjetividade propriamente dita, um campo entre sujeitos.

THE INITIAL TIMES OF MOTHERHOOD: INDIFERENTIATION OR INTERSUBJECTIVITY WITHIN THE MOTHER-INFANT PRIMITIVE RELATIONSHIP?

\footnotetext{
Abstract

The article's main objective is to analyse the maternal function within the psychic birth of the infant, putting a special emphasis in the affective dimension of the exchanges between mother and baby. We aim to discuss Winnicott's concept of primary maternal concern to highlight its paradox: indiferentiation or intersubjectivity? The classical notion proposed by Winnicott will be discussed and articulated to contemporary authors such as Ogden and Roussillon. Those authors propose an in depth study of Winnicotts'contributions, introducing the notion of intersubjectiviy within the area of the primary relationship established between a mother and her baby.
}

Index terms: primary maternal concern; indiferentiation; intersubjectivity; psychoanalysis; mother-baby relationship. 
PRIMEROS TIEMPOS DE LA MATERNIDAD: DESDIFERENCIACIÓN O INTERSUBJETIVIDADE EN LA RELACIÓN PRIMITIVA ENTRE MADRE E HIJO?

\section{Resumen}

Este texto tiene como objetivo analizar la función de el otro mama en la vida psiquica temprana del ninõ, haciendo bincapié en la dimension relacional y fundador de este cambio. En estaperspectiva, tenemos la intención de discutir el concepto de Winnicott de preocupación materna primaria a reflexionar sobre su paradoja: desdiferenciación o intersubjetividad? El enfoque clásico y bien conocido de Winnicott es problematizado a la luz de autores contemporáneos como Ogden y el Rossillón, que viene a proponer una complejización de su pensamiento con la introduccion en la relación primaria entre madre e bijo, de la noción de intersubjetividad.

Palabras clave: preocupación materna primaria; desdiferenciación; intersubjetividade; psicoanálisis; relación madre-hijo.

\section{REFERÊNCIAS}

Badinter, E. (2011) O conflito entre a mulher a mãe. Rio de Janeiro: Record.

Freud, S. (1977a). Projeto para uma psicologia científica. In S. Freud, Ediçâo standard brasileira das obras psicológicas completas de Sigmund Freud (J. Salomão, trad., Vol. 1, pp. 381-456). Rio de Janeiro: Imago. (Trabalho original publicado em 1895)

Freud, S. (1977b). Três ensaios sobre a teoria da sexualidade. In S. Freud, Edição standard brasileira das obras psicológicas completas de Sigmund Freud (J. Salomão, trad., Vol. 7, pp. 123-252). Rio de Janeiro: Imago. (Trabalho original publicado em 1905)

Ogden, T. (1996). Os sujeitos da psicanálise. São Paulo: Casa do Psicólogo.

Ogden, T. (2010). Sobre sustentar e conter, ser e sonhar. In T. Ogden, Esta arte da psicanálise: sonhando sonhos não sonhados e gritos interrompidos (pp. 121-138). Porto Alegre, RS: Artmed.

Roussillon, R. (2008). L'entreje(u) primitif et l'homossexualité primaire “en Double”. In
R. Roussillon, Le jeu et l'entre-je(u) (pp. 117-134). Paris: P.U.F.

Valler, E. H. R. (1990). A teoria do desenvolvimento emocional de D. W. Winnicott. Revista Brasileira de Psicanálise, 24 (2), 155-170.

Winnicott, D. W. (1975). O papel de espelho da mãe e da família no desenvolvimento infantil. In D. W. Winnicott, $O$ brincar e a realidade (pp. 153-162). Rio de Janeiro: Imago. (Trabalho original publicado em 1967)

Winnicott, D. W. (1978a). Preocupação materna primária. In $\mathrm{D}$. W. Winnicott, Textos selecionados: da pediatria à psicanálise (491-498). Rio de Janeiro: Francisco Alves. (Trabalho original publicado em 1956)

Winnicott, D. W. (1978b). Desenvolvimento emocional primitivo (pp. 269-285). In D. W. Winnicott, Da pediatria a psicanálise. Rio de Janeiro: Francisco Alves. (Trabalho original publicado em 1945)

Winnicott, D. W. (1983). Da dependência à independência. In D. W. Winnicott, $O$ ambiente e os processos de maturação: estudos sobre a teoria do desenvolvimento emocional. Porto Alegre, RS: Artes Médicas.

Recebido em fevereiro/ 2014. Aceito em março/2014. 